\title{
Communication Skill in Medicine
}

Health care professionals including doctors need to communicate with patients or their parties in their day to day activities. It is an essential activity of doctors. In the present medical curriculum emphasis has been given to learn communication skill by the future doctors.

How to improve communication between doctors and patients?

Communication difficulties between doctors and patients have been looked at by researchers from several disciplines who have tried to explore why these occur. Mishler, for example, has argued that doctors and patients talk to each other in different voices. The voice of medicine is characterized by medical terminology, objective descriptions of physical symptoms. The voice of patients, on the other hand, is characterized by non-technical terminology about the subjective experience of illness within the context of social relationships and the patient's everyday world. Typically, doctors have more power than patients to structure the nature of the interaction between them. As a consequence, patients may feel that their voice is overridden, silenced, or stripped of personal meaning and social context. To improve communications between doctors and patients we also need to understand the nature of the decision making that is taking place in the consultation.

Why is good communication important?

The communication skill means 'better care for our patients'. There is considerable evidence to show that doctors who communicate well with patients are more likely to:

1. Make an accurate, comprehensive diagnosis.

2. Detect emotional distress in patients.

3. Have patients who are satisfied with the care they have received and who are less anxious about their problem.

4. Have patients who agree with and follow the advice given.
In countries where patients are less likely to sue their doctors, patients still express dissatisfaction about how doctors communicate and relate to them.

\section{Can communication skills be learned?}

Training to be a doctor involves the acquisition of knowledge, skills and appropriate attitudes. Like many aspects of medical education, it was assumed until fairly recently that students acquire good communication skills and appropriate attitudes by a sort of osmosis- by observing and modeling their behavior on that of their teachers.

In the 1970's a series of studies was carried out on medical students during their fourth-year clerkship in psychiatry. The study found that before training, students experienced difficulties in obtaining histories from patients. The difficulties which were highlighted included:

- Not obtaining all the necessary information from the patient.

- Forgetting to ask about the influence of the patient's problems on themselves and their family.

- Failing to notice and respond to verbal and nonverbal cues from the patient.

- Looking bored during the interview.

It was found that the students who had received feedback training were better at communicating with patients.

Patient-Physician communication: Why and How? Patient-physician communication is an integral part of clinical practice. When done well, such communication produces a therapeutic effect for the patient, as has been validated in controlled studies. Formal training programs have been created to enhance and measure specific communication skills. Many of these efforts, however, focus on medical schools and early postgraduate years and, therefore, remain isolated in academic settings. Thus, the communication skills of the busy physician often remain poorly developed, and the need for established physicians to become better communicants continues. 
The manner in which a physician communicates information to a patient is as important as the information being communicated. Patients who understand their doctors are more likely to acknowledge health problems, understand their treatment options, modify their behavior accordingly, and follow their medication schedules.

\section{Why Bother Communicating with patients?}

A Reminder about the value of communication

From obtaining the patient's medical history to conveying a treatment plan, the physician's relationship with his patient is built on effective communication. In these encounters, both verbal and nonverbal forms of communication constitute this essential feature of medical practice.

\section{How to Communicate with Patients}

\section{Reminder for the busy Physician}

Medical professionals debate the best strategies for the effective communication, as well as the ability of these strategies to be taught or evaluated objectively. Certainly, each physician must develop his or her own style of communication. At the same time, many professional and academic organizations have now also defined key elements of communications skills needed by physicians. For example, the Accreditation Council for Graduate Medical Education recommends that physicians become competent in five key communication skills: 1) listening effectively; 2) eliciting information using effective questioning skills; 3 ) providing information using effective explanatory skills; 4) counseling and educating patients; and 5) making informed decisions based on patient information and preference.

\section{Assess What the Patient Already Knows}

Before providing information, find out what the patient already knows about his or her condition. Many times, other physicians or health care providers have already communicated information to the patient, which can have the effect of coloring patient perceptions and perhaps even causing confusion when new information is introduced.

\section{Assess What the Patient Wants to Know}

Not all patients with the same diagnosis want the same level of detail in the information offered about their condition or treatment. Studies have categorized patients on a continuum of information-seeking behavior, from those who want very little information to those who want every detail the physician can offer. Thus, physicians should assess whether the patient desires, or will be able to comprehend, additional information.

\section{Be Empathic}

Empathy is a basic skill physicians should develop to help them recognize the indirectly expressed of their patients. Once recognized, these emotions need to be acknowledged and further explored during the patient-physician encounter.

\section{Slow down}

Physicians who provide information in a slow and deliberate fashion allow the time needed for patients to comprehend the new information. Other techniques physicians can use to allow time include pausing frequency and reinforcing silence with appropriate body language. A slow delivery of with appropriate pauses also gives the listener time to formulate questions, which the physician can then use to provide further bits of targeted information. Thus, a dialogue punctuated with pauses leads to deeper comprehension on both sides.

One study found that physicians typically wait only 23 seconds after a patient begins describing his chief complain before interrupting and redirecting the discussion. Such premature redirection can lead to late-arising concerns and missed opportunities to gather important data.

As a side note, patient satisfaction is also greater when the length of the office visit matches his or her pre-visit expectation. In situations involving the delivery of bad news, the technique of simply stating the news and pausing can be particularly helpful in ensuring that the patient and patient's family fully receive and understand the information. Allowing this time for silence, tears, and questions can be essential.

\section{Keep it Simple}

Physicians should avoid engaging in long monologues in front of the patient. Far better for the physician to keep to short statements and clear, simple explanations.

\section{Tell the Truth}

It is important to be truthful. In addition, it is important that physicians not minimize the impact of 
what they are saying. Saying that a patient has 'gone' or has 'left us,' for an example, could be interpreted by an anxious family member as meaning that the patient has left his room to have a radiologic film taken or to undergo a test. Alternatively, physicians who use "D" words (eg, dying, died, dead) when appropriate, effectively communicate and minimize confusion.

\section{Be Hopeful}

Although the need for truth-telling remains primary, the therapeutic value of conveying hope in situations that may appear hopeless should not be underestimated. Particularly in the context of terminal illness and end-of-life care, hope should not be discouraged.

For example, in situations such as the imminent death of a patient, hope can be conveyed to the family by assuring them that therapy can be effective in allaying pain and discomfort. Thus, even when physicians must convey a grim prognosis to a patient or must discuss the same with family members, being able to promise comfort and minimal suffering has real value.

\section{Watch the Patient's Body and Face}

Much of what is conveyed between a physician and patient in a clinical encounter occurs through nonverbal communication.

For both physician and patient, images of body language and facial expressions will likely be remembered longer after the encounter than any memory of spoken words.

It is also important to recognize that the patientphysician encounter involves a two way exchange of nonverbal information. Patient's facial expressions are often good indicators of sadness, worry, or anxiety. The physician who responds with appropriate concern to these nonverbal cues will likely impact the patient's illness to a greater degree than the physician wanting to strictly convey factual information.

\section{Be Prepared for a Reaction}

Patients vary, not only in their willingness and ability to absorb information, but in their reactions to physician communications. Most physicians quickly develop a sense for the various coping styles of patients, a range of human reactions that has been categorized in several specific clinical settings.

In responding to any of these patient reactions, it is important to be prepared. The first step is for the physician to recognize the response, allowing sufficient time for a full display of emotions. Most importantly, the physician simply needs to listen quietly and attentively to what the patient or family is saying. Sometimes, the physician can encourage patients to express emotions, perhaps even asking them to describe their feelings. The physician's body language can be crucial in conveying empathic concern in these encounters.

\section{Conclusion:}

Simple choices in words, information depth, speech patterns, body position, and facial expression can greatly affect the quality of one-to-one communication between the patient and physician. To a large degree, these are conscious choices that can be learned and customized by the physician to fit particular patients in clinical situations. Avoiding communications pitfalls and sharpening the basic communication skills can help strengthen the patientphysician bond that many patients and physicians believe is lacking.

There is no shortcut for physician-patient interaction. We have to acknowledge the need of good physicianpatient interaction for wide range of benefit out of it. It is our collective responsibility to teach our 'future doctors' this important but basic skill in medicine.

\section{Md. Rajibul Alam}

Professor of Medicine, Sir salimullah Medical College, Dhaka

Md. Abul Faiz

Professor of Medicine \&Principal

Dhaka Medical College, Dhaka.

(J Bangladesh Coll Phys Surg 2007; 25 : 115)

\section{Further reading:}

1. Mishler E G (1984) The Discourse of Medicine: dialectics of medical interviews. Ablex, Norwood, NJ.

2. Silverman J, Kurtz S and Drapper J (eds) (2005) Skills for Communicating with Patients. Radcliffe Publishing Limited, Oxford.

3. Lloyd M and Bor R (1996) Communication Skills for Medicine. Churchill Livingstone, New York. 